\title{
Prevalence and antibiotic resistance profile of Listeria spp. associated with seafoods from fish catchment areas in Kerala, India
}

\author{
K. Vrinda Menon ${ }^{1}$ (D), B. Sunil2 (i) and C. Latha ${ }^{3}$ (D)
}

1. Department of Veterinary Public Health, College of Veterinary and Animal Sciences, Kerala Veterinary and Animal Sciences University, Thrissur, Kerala, India; 2. Department of Veterinary Public Health, College of Veterinary and Animal Sciences, Veterinary and Animal Sciences University, Thrissur, Kerala, India; 3. Department of Veterinary Public Health, College of Veterinary and Animal Sciences, Veterinary and Animal Sciences University, Mannuthy, Thrissur, Kerala, India.

Corresponding author: K. Vrinda Menon, e-mail: vrinda@kvasu.ac.in

Co-authors: BS: sunil@kvasu.ac.in, CL: latha@kvasu.ac.in

Received: 09-07-2020, Accepted: 03-02-2021, Published online: 27-03-2021

doi: www.doi.org/10.14202/vetworld.2021.777-783 How to cite this article: Vrinda Menon K, Sunil B, Latha C (2021) Prevalence and antibiotic resistance profile of Listeria spp. associated with seafoods from fish catchment areas in Kerala, Veterinary World, 14(3): 777-783.

\begin{abstract}
Background and Aim: Listeria monocytogenes is a ubiquitous, intracellular pathogen which has been implicated as a cause of several foodborne outbreaks. This study aimed to generate information on the prevalence and antibiotic resistance profile of Listeria species isolated from seafood.
\end{abstract}

Materials and Methods: A total of 400 samples of fresh fish, 100 samples of dry fish and 200 samples each of crustaceans and mollusks were collected from the fish catchment areas. All the samples were subjected to isolation and identification of Listeria spp. by two-step enrichment in UVM broth and plating on selective agar media (PALCAM) and then subjected to molecular characterization. L. monocytogenes isolates obtained during the study were subjected to serotyping by multiplex polymerase chain reaction. The isolates were also subjected to antibiotic sensitivity test.

Results: The prevalence of $L$. monocytogenes in seafoods in the present study was $0.55 \%$. The isolates of $L$. monocytogenes were found to possess all virulence genes, namely, $i a p, h l y \mathrm{~A}, \operatorname{act} \mathrm{A}, \operatorname{prf\mathrm {A}}, p l c \mathrm{~A}$, and $i n l \mathrm{~A}$. All the isolates belonged to serotype $4 \mathrm{~b}$. The occurrence of Listeria innocua was found to be more and was detected in $16.77 \%$ of seafood samples. Antibiotic sensitivity test revealed that all isolates were resistant to cefixime but were sensitive to almost all other commonly used antibiotics.

Conclusion: The presence of Listeria spp. in raw seafood samples augments the need for implementation of good hygienic practices during the handling and processing of seafoods to safeguard the health of the consumers.

Keywords: Antibiotic, Kerala, Listeria, seafoods, serotype.

\section{Introduction}

Listeria monocytogenes is one among the many causative agents of foodborne diseases in humans. The intracellular pathogen has been implicated in several outbreaks of foodborne diseases. The genus Listeria currently includes 17 recognized species of small rod-shaped Gram-positive bacteria [1]. The ubiquitous nature of Listeria spp. allows easy access of this pathogen to a variety of raw foods, including seafoods [2]. In spite of the wide distribution of the microorganism in the environment and relatively high frequency of isolation in foods, the incidence of listeriosis is low in the general population. The incidence of systemic listeriosis is much higher in individuals with compromised immune systems. The ingested organisms can breach endothelial and epithelial barriers of the infected host including the intestinal,

Copyright: Vrinda Menon, et al. Open Access. This article is distributed under the terms of the Creative Commons Attribution 4.0 International License (http://creativecommons.org/licenses/ by/4.0/), which permits unrestricted use, distribution, and reproduction in any medium, provided you give appropriate credit to the original author(s) and the source, provide a link to the Creative Commons license, and indicate if changes were made. The Creative Commons Public Domain Dedication waiver (http:// creativecommons.org/publicdomain/zero/1.0/) applies to the data made available in this article, unless otherwise stated. blood-brain, and placental also [3]. According to the WHO, listeriosis is a relatively rare disease with 0.1 10 cases per 1 million people per year, depending on the countries and regions of the world. Despite the fact that the number of cases of listeriosis is low, the high rate of death associated with this infection makes it a significant public health concern. The antibiotic sensitivity profile of Listeria spp., however, varies with the use of drugs in human and veterinary medicine in different geographical areas. Inappropriate use of antibacterial drugs is the major cause of acquired resistance in Listeria species [4]. Multiple drug resistance in L. monocytogenes strains isolated from fish, raw and ready-to-eat seafood product samples has been reported [5]. Therefore, continuous focus on antibiotic-resistant Listeria isolates is essential to circumvent future risks to the human population.

The consumption of seafoods has increased globally because of its easy digestibility, high-quality protein content, and good source of lipids with high levels of unsaturated fatty acids [6]. The global proliferation of pathogens, especially Listeria spp. through seafood, is a major concern as it frequently triggers regulatory alerts in importing countries. Sporadic cases of foodborne listeriosis associated with seafoods have been 
reported across the globe for the past few decades. Extensive studies to assess the presence of Listeria spp., in the major fish catchment areas, have been very few in Kerala, India. With the advent of globalization of trade, ensuring the quality of seafood for exporting country like India becomes important for acceptability in the international market and for good economic returns [7].

This study aimed to generate information on the prevalence and antibiotic resistance profile of Listeria species isolated from seafoods.

\section{Materials and Methods}

\section{Ethical approval}

Ethical approval was not necessary for this study. However, samples were collected as per standard collection procedure.

\section{Study area and period}

Seafood samples were collected from fish catchment area in coastal districts of Kerala from December 2013 to January 2015. The fish including dry fish, crustaceans, and mollusks were collected from Kozhikode (Puthiyappa harbor), Kollam (Neendakara), Thiruvananthapuram (Vizhinjam, Shangumugham), Alappuzha, and Thrissur (Chavakkad) districts in Kerala.

\section{Sampling}

A total of 400 samples of marine fish, namely, sardine, mackerel, tuna, fin bream, anchovy, and milkfish were collected from the five coastal districts of Kerala. A total of 200 samples each of crustaceans (prawn and crabs) and mollusks (squid, mussels, and clams) were also collected from the areas under study. The fish, mollusks, and crustacean samples were collected soon after unloading from the boats in the harbor except in Alappuzha and Thrissur districts where the samples were collected after it was stored in ice. The dry fish samples stored at $25^{\circ} \mathrm{C}$ ( 25 samples each from five districts) were collected from retail outlets near the harbors which mainly included two species of fish, namely, tongue sole and silver belly. The samples were collected in UV sterilized polyethylene bags and were brought to the laboratory in thermocol containers and immediately subjected to microbiological analysis.

\section{Isolation of Listeria species}

The modification of the USDA [8] and FDA [9] protocols was used for the isolation of Listeria spp. It included a two-step enrichment of the sample in University of Vermont broth (UVM I) for $24 \mathrm{~h}$ at $37^{\circ} \mathrm{C}$ followed by inoculation in UVM II broth for $48 \mathrm{~h}$ at $37^{\circ} \mathrm{C}$. The selective plating after enrichment was done in Polymyxin-AcriflavineLithium Chloride-Ceftazidime-Aesculin-Mannitol (PALCAM) (HiMedia) agar. The morphologically typical gray-green colonies with black sunken centers were verified by Gram's staining and motility test and were also subjected to biochemical tests, that is, methyl red, Voges-Proskauer, sugar fermentation tests (rhamnose, mannitol, and xylose), catalase test, and Christie Atkins Munch Petersen (CAMP) test which are specific for Listeria spp. [10]. The positive isolates were further confirmed by molecular confirmation by polymerase chain reaction (PCR).

\section{Molecular confirmation of isolates}

The DNA template for PCR was prepared by simple boiling and snap chilling method. PCR was standardized for the detection of genus-specific $16 \mathrm{~S}$ rRNA followed by the standardization of six virulence genes which encode for phosphatidylinositol phosphatase $\mathrm{C}$ activity ( $p l c A)$ (1484 bp), regulatory activity ( $p r f A$ ) (1060 bp), actin polymerization protein (actA) (839 bp), hemolysin activity (hlyA) (456 bp), p60 protein (iap) (131 bp), and internalin A protein (inlA) (800 bp) [11,12]. The standardization was done using L. monocytogenes standard strain MTCC 1143 obtained from IMTECH, Chandigarh. The suspected Listeria innoсиа isolates were confirmed by subjecting the isolates to iap gene. The genes were standardized using standard strain L. innocua (ATCC 33090). The iap gene encoding $\mathrm{p} 60$ protein was used as a target which is common to all members of the genus Listeria. The isolates of L. innocua showing weak hemolysis on blood agar plates were also subjected to hlyA gene to study their virulence.

\section{Serotyping of $L$. monocytogenes isolates}

In this study, PCR was used to classify L. monocytogenes into different serogroups [13]. The multiplex PCR was performed using four sets of primers, namely, Imo0737, Imo1118, ORF2819, and ORF2110 with an amplification size of $906 \mathrm{bp}, 690 \mathrm{bp}, 471 \mathrm{bp}$, and $597 \mathrm{bp}$, respectively. This serogrouping was based on the fact that $L$. monocytogenes serotypes $1 / 2 \mathrm{a}, 1 / 2 \mathrm{~b}$, $1 / 2 \mathrm{c}$, and $4 \mathrm{~b}$ were responsible for $98 \%$ of documented listeriosis cases [14].

\section{Antibiotic susceptibility testing of the isolates}

All Listeria isolates were subjected to antibiotic sensitivity test against 12 different antimicrobial agents by agar diffusion method in Mueller-Hinton AGAR [15]. Listeria isolates were tested against amoxicillin $(10 \mu \mathrm{g})$, cefixime $(10 \mu \mathrm{g})$, chloramphenicol $(25 \mu \mathrm{g})$, furazolidone $(100 \mu \mathrm{g})$, co-trimoxazole $(25 \mu \mathrm{g})$, oxytetracycline $(30 \mu \mathrm{g})$, erythromycin $(15 \mu \mathrm{g})$, chlortetracycline $(30 \mu \mathrm{g})$, streptomycin $(10 \mu \mathrm{g})$, and nitrofurazone $(100 \mu \mathrm{g})$, neomycin $(10$ $\mu \mathrm{g})$, doxycycline hydrochloride $(30 \mu \mathrm{g})$, and antibiotic discs (HiMedia, Mumbai). The clinical breakpoints for Listeria susceptibility testing were defined according to the Clinical and Laboratory Standard Institute [16] and the isolates were grouped as sensitive, intermediary sensitive, and resistant against each antibiotic.

\section{Statistical analysis}

Data were analyzed statistically using software SPSS Version 21 (IBM, NY, USA).

\section{Results}

\section{Occurrence of Listeria species in seafoods}

Out of the 900 seafood samples screened, colonies from 156 samples showed characteristics of 
Listeria spp. in selective media which were later confirmed by biochemical tests. The results were further confirmed by the pathogenicity assay. Only isolates from five samples were positive for beta-hemolysis by CAMP test with Staphylococcus aureus and were confirmed as L. monocytogenes. L. monocytogenes isolates obtained were subjected to genus-specific 16S rRNA followed by the presence of six virulence genes. All the isolates of $L$. monocytogenes obtained revealed the presence of all six virulence genes (Figure-1). L. monocytogenes was isolated from dry fish (tongue sole), fish (Tuna), mollusks (mussels), and crustacean (prawns) samples. The remaining samples showing positivity in selective medium were found to be L. innocua when subjected to biochemical tests. The details of the samples found positive for Listeria spp. in different districts and from different species of seafoods are shown in Table-1.

L. innocua isolates were confirmed by subjecting the isolates to PCR targeting genus-specific $16 \mathrm{~S}$ r RNA and iap gene. The occurrence of L. innocua in catchment areas of Kozhikode, Kollam, Thrissur, Thiruvananthapuram, and Alappuzha districts was $18.91,34.59,10.81,12.43$, and $7.56 \%$, respectively. L. innocua isolates positive for iap gene are shown in Figure-2. Moreover, the prawn isolates obtained from Thrissur were found positive for the presence of hly $A$ gene (Figure-3). The maximum prevalence of Listeria spp. was observed in crustaceans followed by fishes and mollusks. The overall prevalence of Listeria spp. in seafoods was found to be $17.33 \%$.

Statistical analysis of data using Chi-square multiple proportion test was done to know whether there was any significant difference between the prevalence of organism in different districts. This was followed by "Z" test, between the districts in which the organism was present. The results have shown that the presence of organism in Kollam was significantly higher compared to other districts $(\mathrm{p}<0.01)$.

\section{Serotyping of $\boldsymbol{L}$. monocytogenes isolates}

L. monocytogenes isolates obtained during the study were subjected to serotyping using multiplex PCR with four sets of primers, namely, Imo0737, Imo1118, ORF2819, and ORF2110. This serogrouping was based on the fact that $L$. monocytogenes serotypes $1 / 2 \mathrm{a}, 1 / 2 \mathrm{~b}, 1 / 2 \mathrm{c}$, and $4 \mathrm{~b}$ are responsible for $98 \%$ of documented listeriosis cases. The results indicated that all the isolates from fish, dry fish, mussels, and prawn samples revealed an amplification of $597 \mathrm{bp}$. Hence, it was concluded that the isolates belonged to Lineage I and the probable serotype was $4 \mathrm{~b}$, as shown in Figure-4.

\section{Antibiotic susceptibility testing of the isolates}

The antibiotic sensitivity pattern of Listeria isolates from seafoods revealed that most of them were sensitive to the antibiotics under study. All isolates

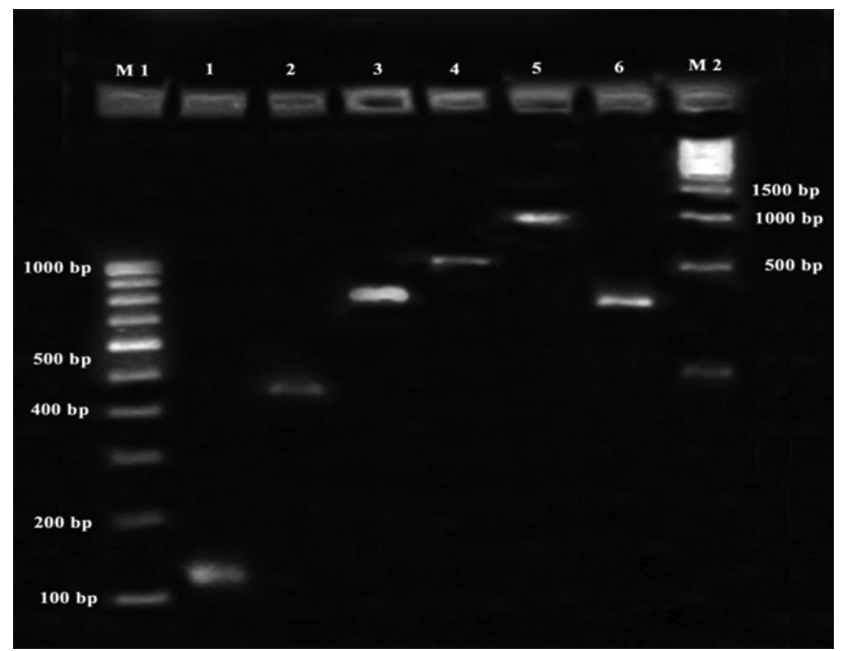

Figure-1: Polymerase chain reaction profile of Listeria monocytogenes isolate obtained with six virulence associated genes. Lane M: 100 bp ladder, lane 1: iap gene (131 bp), lane 2: hly A gene (456 bp), lane 3: act A gene (839 bp), lane 4: prf A gene (1060 bp), lane 5: plc A gene (1484 bp), lane 6: Inl A gene ( 800 bp), lane M: 500 bp ladder.

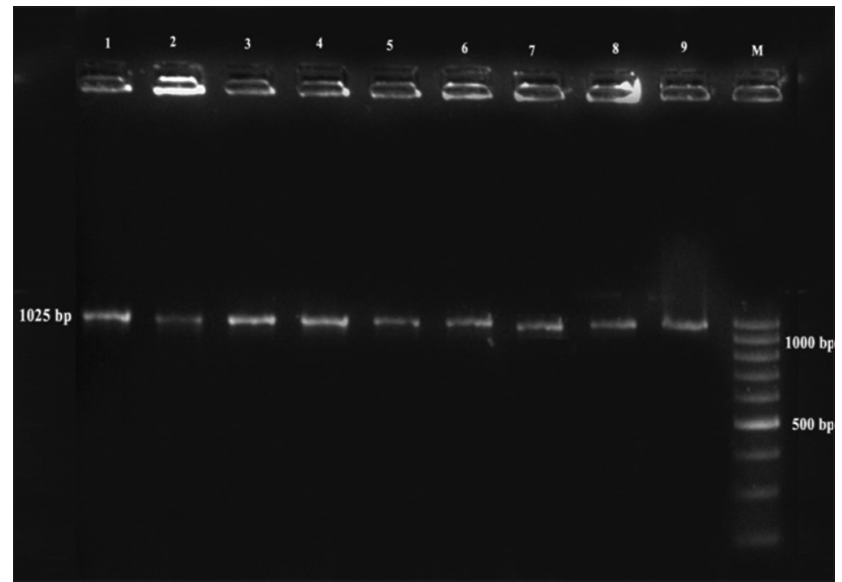

Figure-2: Polymerase chain reaction profile of Listeria innocua isolates from seafoods. Lane M: 100 bp ladder, lane 1-10: Isolates from seafoods.

Table-1: District-wise distribution of Listeria innocua in seafoods.

\begin{tabular}{|c|c|c|c|c|c|}
\hline \multirow[t]{2}{*}{ District } & \multicolumn{4}{|c|}{ Number of samples positive for Listeria spp. } & \multirow[t]{2}{*}{ Total 900} \\
\hline & Fishes 400 & Dry fish 100 & Crustacean 200 & Mollusks 200 & \\
\hline Kozhikode & 21 & 2 & 4 & 8 & 35 \\
\hline Thrissur & 14 & 1 & 3 & 2 & 20 \\
\hline Alappuzha & 10 & 0 & 2 & 2 & 14 \\
\hline Kollam & 20 & 1 & 35 & 8 & 64 \\
\hline Thiruvananthapuram & 14 & 1 & 3 & 5 & 23 \\
\hline Total & 78 & 4 & 47 & 22 & 156 \\
\hline
\end{tabular}




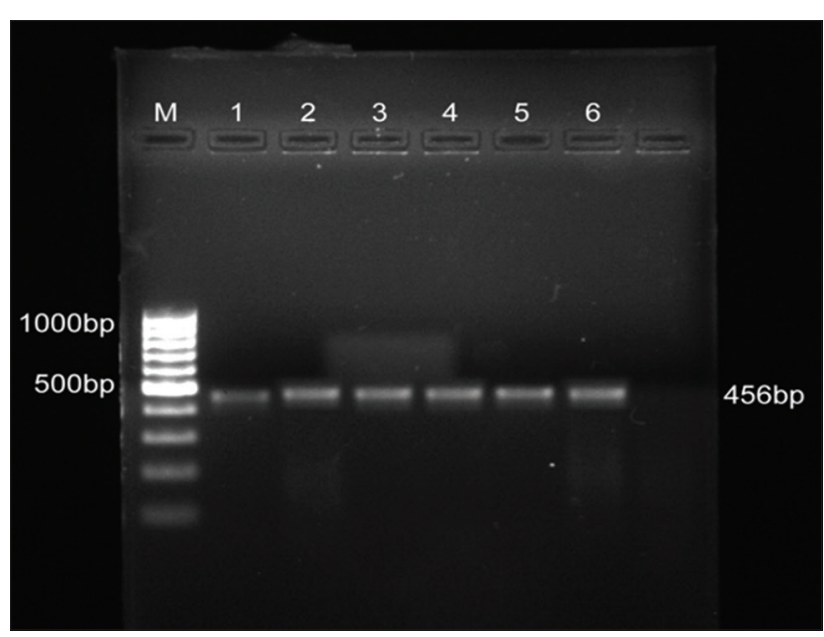

Figure-3: Polymerase chain reaction profile of Listeria innocua positive for h/yA. Lane $\mathrm{M}$ : $100 \mathrm{bp}$ ladder, lane 1: BD1, lane 2: P1, lane 3: P2, lane 4: H6, lane 5: 1143, Lane 6: $\mathrm{H} 10$.

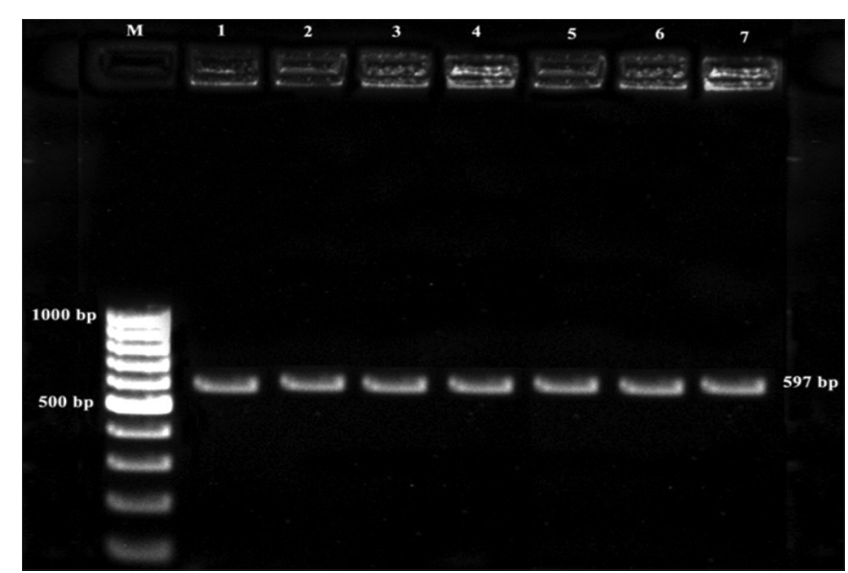

Figure-4: Multiplex PCR profile for serotyping of L. monocytogenes isolates. Lane M: 100 bp ladder, Lane1: Dry fish, Lane 2: Prawn, Lane 3: Mussels-1, Lane 4: Mussels-2, Lane 5: Fish Lane 6: Prawn 2, Lane 7: 1143.

were resistant to cefixime. The isolates from dry fish showed intermediate resistance toward chlortetracycline, furazolidone, nitrofurazone, and cotrimoxazole but fresh fish isolates were sensitive to aforesaid antibiotics. All $L$. innocua isolates were sensitive to most of the antibiotics understudy but intermediate resistance was shown against nitrofurazone, cotrimoxazole, streptomycin, and amoxicillin. The maximum intermediate resistance against nitrofurazone (70.21\%) was obtained from isolates obtained from crustaceans. L. innocua isolates obtained from mollusks also revealed resistance against cotrimoxazole $(4.54 \%)$ and oxytetracycline $(9.1 \%)$.

\section{Discussion}

The present investigation revealed an overall prevalence of $0.55 \%$ and $16.77 \%$ of L. monocytogenes and $L$. innocua, respectively, in seafoods collected from catchment areas of five coastal districts of Kerala. The occurrence of L. monocytogenes in fish, dry fish, prawn, and mussels was found to be $0.25 \%$,
$2 \%, 0.5 \%$, and $1 \%$, respectively. The possible route of contamination may be attributed to the spread of the organism from the intestinal contents of fish to other tissues or through cross-contamination from contaminated surfaces, improper handling, and inappropriate transport. However, a higher prevalence of L. monocytogenes $(2.7 \%)$ was observed in marine fish and fish products in Kerala [17] than in the present study. Higher prevalence of L. monocytogenes in fishes collected from Kerala, Iran, and Northeast India than the present study has also been recorded [17-19] with a prevalence of $1.66,2.55$, and $1.8 \%$, respectively. Moreover, a higher prevalence of $6.32 \%$ in marine aquatic products in China was reported [16], which was higher than the present study. The variation in the results in different studies is related to differences in the rate of seafood contamination, isolation, and identification methodologies. The prevalence of L. monocytogenes in $2 \%$ of the dry fish samples in the present study was lower than the report of 5\% in Kerala [20] but higher than the recent report in Kerala [17] where the organism could not be detected from dry fishes. The presence of the organism in dry fish in the present study could be attributed to the presence of the organism in fresh fish where the organism could have survived in the presence of less competitive bacteria, low water activity, and increased salinity. The isolation of L. monocytogenes in raw seafoods may pose a risk in kitchen through cross-contamination by handling cooked and raw foods, contamination from fish cleaning areas, and cutting board surface. Hence, avoidance of consumption of insufficiently cooked seafoods, especially by immunosuppressed individuals, is recommended.

Listeria innocua was the predominant species isolated from seafoods with a prevalence of $19.5 \%$, $4 \%, 23.5 \%$, and $11 \%$ from fish, dry fish, crustaceans, and mollusks, respectively. The increased occurrence of $L$. innocua in shellfishes may be attributed to their filter feeding habit which concentrates the microorganisms in their tissues. The prevalence of $L$. innocua $(17.2 \%)$ reported in marine fishes and fish products [17] were in accordance with the present investigation. This finding is in agreement with some previous studies $[1,5,20]$ who had reported a predominance of $L$. innocua in seafood samples procured from Goa, Cochin (Kerala), and Greece, respectively. The higher occurrence of $L$. innocua as compared to L. monocytogenes could be due to the fact that $L$. innocua has a shorter generation time than other Listeria spp. [11] and the recovery of $L$. monocytogenes using selective broth was lower when $L$. innocua was present. Moreover, L. monocytogenes and L. innocua share the same ecological niche and L. innocua could be used as an indicator for the presence of L. monocytogenes [21].

The occurrence of the organisms in seafoods suggests the need for environmental sanitation to control the organism in raw seafoods. In the present study, all $L$. monocytogenes isolates obtained and confirmed 
by culture techniques were found to be positive for the presence of all the six virulence genes. Similarly, the presence of all six virulence genes in L. monocytogenes isolates from clinical and environmental samples [22] and seafood samples [23] was also reported. The presence of six important virulence genes indicates that L. monocytogenes isolates in seafoods were capable of producing severe foodborne infections. The screening of other isolates based on PCR amplification of iap gene which encodes for $\mathrm{p} 60$ protein was confirmative of $L$. innocua. The presence of PCR product size of 1025 bp for $L$. innocua isolates from seafoods has been reported [24]. Weak hemolysis on blood agar and presence of hly A gene in L. innocua isolates from prawn samples was also observed in the present study which was in accordance with the reports which revealed the presence of atypical $L$. innocua strains (positive for $h l y \mathrm{~A}$ ) among the isolates from food and environment by PCR [23]. These atypical L. innocua isolates could represent a stage in the evolution of $L$. innocua from a common ancestor of $L$. monocytogenes and might present a risk to human health [23]. Moreover, these atypical strains may constitute a reservoir of virulence genes transferable to other species of the same genus.

L. monocytogenes isolates obtained from seafoods were subjected to serotype identification by PCR. The results revealed that all the isolates belonged to serotype $4 \mathrm{~b}$ which comes under lineage I. According to the previous studies, it has been observed that L. monocytogenes isolated from fish, fish products, and fish processing plants most often belonged to serotype $1 / 2 \mathrm{a}$ and $4 \mathrm{~b}[25,26]$. The results of earlier studies also revealed that more than $98 \%$ of infections were caused by serotypes $1 / 2 \mathrm{a}, 1 / 2 \mathrm{~b}, 1 / 2 \mathrm{c}$, and $4 b[18,27]$. Serotype $4 b$ has been identified as the predominant serotype from raw fish [5], vegetable, soil clinical samples, and foods of animal origin [22]. However, the predominant serotype of L. monocytogenes from fish isolates in China belonged to serotype $1 / 2 \mathrm{c}$ [16] which differs from the findings of the present study and could be attributed to the regional differences and type of contamination. Serotype $4 \mathrm{~b}$ has been implicated in majority of the foodborne outbreaks and has been implicated as the major cause of epidemics in humans and animals.

All Listeria isolates obtained from seafood samples showed sensitivity to erythromycin, chloramphenicol, doxycycline, chlortetracycline, and neomycin. The susceptibility of $L$. monocytogenes isolates to chloramphenicol and tetracycline was reported [28] which was in agreement with the present study. The isolates from dry fish showed intermediary resistance towards chlortetracycline, furazolidone and cotrimoxazole but fresh fish isolates were sensitive to aforesaid antibiotics. The efficiency of cotrimoxazole against $L$. monocytogenes as observed in the present study is in agreement with an earlier report [17]. A lower resistance to tetracycline and
$100 \%$ susceptibility to streptomycin by Listeria isolates were observed [29] which were similar to the findings of the present study. The resistance of the isolates obtained from mollusks against cotrimoxazole and oxytetracycline was $4.54 \%$ and $9.1 \%$, respectively. However, all other isolates were resistant to cefixime and sensitive to all other antibiotics under study. Similar findings on resistance to cephalosporin (ceftriaxone) against Listeria isolates obtained from foods were observed [30] which are in accordance with the present study. However, resistance to cefixime can be explained by the organism's natural resistance to the antibiotic which is due to the minimal or non-existent affinity of listerial penicillin-binding protein 3 and 5 for cephalosporins [31]. All the isolates of L. innocua in the study were sensitive to chloramphenicol erythromycin doxycycline and neomycin. The reports of the sensitivity of the organism toward erythromycin and chloramphenicol [2] were in accordance with the present study. Mussels and fish isolates of L. innocua revealed intermediate resistance to nitrofurazone. The intermediate resistance to antibiotics is mainly due to the exchange of genetic material (antibiotic resistance genes) which may be due to persistence of Listeria in common environment [32]. Although the antibiotic resistance profiling of the isolates was not alarming, the chances of bacteria acquiring resistance to more drugs cannot be ruled out as the transfer of antibiotic resistance from other bacteria to Listeria has already been established.

\section{Conclusion}

The prevalence of Listeria spp. from raw seafoods indicates a significant public health hazard. However, a high occurrence of L. innocua is an area of concern as the more pathogenic L. monocytogenes species share same ecological niche. Conscientious enforcement of sanitary conditions in fish handling areas, appropriate storage conditions, and personal hygiene practices would help to reduce the potential contamination of raw seafoods with Listeria spp. at the retail level and further reduce the bacterial load in the processed fish products. The antibiotic susceptibility pattern of the organism warrants the need for cautious use of these antimicrobials for use in veterinary and medical practice. Thus, there is a need for continual monitoring of the organism in for seafood exporting state like Kerala, as the organism frequently triggers regulatory alerts from importing countries. Moreover, the regular assessment and understanding of the antibiotic resistance pattern will help to effectively control the emergence of Listeria species in the region.

\section{Authors' Contributions}

KVM, BS, and CL: Designed the work. KVM collected the samples. KVM: Examined the samples in the research laboratory. All authors compiled, read, revised, and approved the final manuscript. 


\section{Acknowledgments}

The authors gratefully acknowledge the Indian Council of Agricultural Research for providing funds under the project "Outreach program on zoonotic diseases" (Grant No F2-2/OPZD/VPH/2009-10 dt 4-2-2010) for the research and Kerala Veterinary and Animal Sciences University for providing the infrastructure and funds for the study.

\section{Competing Interests} interests.

The authors declare that they have no competing

\section{Publisher's Note}

Veterinary World remains neutral with regard to jurisdictional claims in published institutional affiliation.

\section{References}

1. Orsi, R.H. and Wieldmann, M. (2016) Characteristics and distribution of Listeria spp., including Listeria species newly described since 2009. Appl. Microbiol. Biotechnol., 100(12): 5273-5287.

2. Sunil, B., Latha, C., Ajaykumar, V.J., Menon, K.V. and Kumar, A. (2013) Occurrence of Listeria organisms in the shrimp samples from a fishing harbour in Kerala, India. In: Proceedings of eighteenth International Symposium on Problems of Listeriosis, 19-22, September, 2013, Goa, India. p167.

3. Parihar, V.S., Barbuddhe, S.B., Danielsson-Tham, M.L. and Tham, W. (2008) Isolation and characterization of Listeria species from tropical seafoods. Food Control, 19(6): 566-569.

4. Okorie-Kanu, O.J., Anyanwu, M.U., Ezenduka, E.V., Mgbeahuruike, A.C., Okorie-Kanu, C.O., Ugwuijem, E.E., Idogwu, M.N., Anyaoha, C.O., Majesty-Alukagberie, O.L., Vidal, R.O. and Vidal, M. (2020) Occurrence and antibiogram of Listeria species in raw pork, beef, and chicken meats marketed in Enugu State, Southeast Nigeria. Vet. World, 13(2): 317-325.

5. Jamali, H., Paydar, M., Ismail, S., Looi, S.Y., Wong, W F., Radmehr, B. and Abedini, A. (2015) Prevalence, antimicrobial susceptibility and virulotyping of Listeria species and Listeria monocytogenes isolated from open-air fish markets. BMC Microbiol., 15: 144-150.

6. Ghanbari, M., Jami, M., Domig, K.J. and Kneifel, W. (2013) Seafood biopreservation by lactic acid bacteria-a review. LWT Food Sci. Technol., 50(2): 315-324.

7. Menon, K.V., Sunil, B., Latha, C. and Kumar, A. (2017) Critical control points of Listeria species in two major fish catchment areas of Kerala, India. Vet. Sci. Res. J., 8(1-2): 20-25.

8. McClain, D. and Lee, W.H. (1988) Development of USDAFSIS for isolation of Listeria monocytogenes from raw meat and poultry. J. Assoc. Off. Anal. Chem. 71(3): 660-663.

9. Lovett, J. (1988) Isolation and enumeration of Listeria monocytogenes. Food Technol., 42(4): 172-175.

10. Barrow, C.J. and Feltham, R.K.A. (1993) Cowan and Steel's Manual for the Identification of Medical Bacteria. 3rd ed. Cambridge Press, London. p238.

11. Curiale, M.S. and Lewus, C. (1994) Detection of Listeria monocytogenes in samples containing Listeria innocua. $J$. Food Prot., 57(12): 1048-1051.

12. Rawool, D.B., Malik, S.V.S., Shakuntala, I., Sahare, S.B. and Barbuddhe, S.B. (2007) Detection of multiple virulence associated genes in Listeria monocytogenes isolated from bovine mastitis cases. Int. J. Food Mircobiol., 113(2): 201-207.
13. Doumith, M., Buchrieser, C., Glaser, P., Jacquet, C. and Martin, P. (2004) Differentiation of the major L. monocytogenes serovars by multiplex PCR. J. Clin. Microbiol., 42(9): 3819-3822.

14. Borucki, M.K. and Call, D.R. (2003) Listeria monocytogenes serotype identification by PCR. J. Clin. Microbiol., 41(12): 5537-5540.

15. Clinical and Laboratory Standards Institute. (2017) Performance Standards for Antimicrobial Susceptibility Testing. Twenty Seventh Informational Supplement. Clinical and Laboratory Standards Institute, Wayne, Pennsylvania, USA. p250.

16. Chen, M., Cheng, J., Wu, Q., Zhang, J., Chen, J., Xue, L., Lei, T., Zeng, H., Wu, S., Ye, Q., Bai, J. and Wang, J. (2018) Occurrence, antibiotic resistance, and population diversity of Listeria monocytogenes isolated from fresh aquatic products in China. Front. Microbiol., 19(9): 1-11.

17. Basha, K.A., Kumar, N.A., Das, V., Reshmi, K., Rao, B.M., Lalitha, K.V. and Joseph, T.C. (2019) Prevalence, molecular characterization, genetic heterogeneity and antimicrobial resistance of Listeria monocytogenes associated with fish and fishery environment in Kerala, India. Lett. Appl. Microbiol., 69(4): 286-229.

18. Abdollahzadeh, E., Ojagh, E.A., Hosseini, H., Irajian, G. and Ghaemi, E.A. (2016) Prevalence and molecular characterization of Listeria spp. and Listeria monocytogenes isolated from fish, shrimp, and cooked ready-to-eat (RTE) aquatic products in Iran. LWT Food Sci. Technol., 73: 205-211.

19. Pegu, R., Sen, A., Shakuntala, I., Kumar, A. and Ahmed, G. (2017) Prevalence of Listeria monocytogenes in freshwater fish of Northeast India and their molecular characterization by PCR. Indian J. Hill Farming, 30(2): 220-226.

20. Das, S., Lalitha, K.V., Thampuran, N. and Surendran, P.K. (2013) Isolation and characterization of Listeria monocytogenes from tropical seafood of Kerala, India. Ann. Microbiol., 63(3): 1093-1098

21. King, W., Raposa, S.M., Warshaw, J.E., Johnson, A.R., Lane, D., Klinger, J.D. and Halbert, D.N. (1990) A colorimetric assay for the detection of Listeria using nucleic acid probes. In: Miller, A.J., Smith, J.L. and Somkuti, G.A., editors. Foodborne Listeriosis. Elsevier Science Publishers, New York. p117-124.

22. Ajaykumar, V.J. (2014) Isolation and Molecular Characterisation of Listeria monocytogenes from Different Sources, Ph.D. Thesis. Kerala Veterinary and Animal Sciences University, Pookode. p143.

23. Momtaz, H. and Yadollah, S. (2013) Molecular characterization of Listeria monocytogenes isolated from fresh seafood samples in Iran. Diagn. Pathol., 8: 149.

24. Jeyasekaran, G., Karunasagar, I. and Karunasagar, I. (1996) Incidence of Listeria spp. in tropical fish. Int. J. Food Microbiol., 31(1-3): 333-340.

25. Jami, M., Ghanbari, M., Zunabovic, M. and Domig, K.J. (2014) Listeria monocytogenes in aquatic food products-a review. Compr. Rev. Food Sci. Food Saf., 13(5): 798-813.

26. Skowron, K., Wiktorczyk, N., Grudlewska, K., WałeckaZacharska, E., Paluszak, Z., Kruszewski, S. and Gospodarek-Komkowska, E. (2019) Phenotypic and genotypic evaluation of Listeria monocytogenes strains isolated from fish and fish processing plants. Ann. Microbiol., 69: 469-482.

27. Lee, S., Chen, Y., Gorski, L., Ward, T.J., Osborne, J. and Kathariou, S. (2018) Listeria monocytogenes source distribution analysis indicates regional heterogeneity and ecological niche preference among serotype $4 \mathrm{~b}$ clones. mBio, $9(2)$ : e00396-e00418.

28. Abdollahzadeh, E.A., Ojagh, A.S.M., Hosseini, H., Ghaemi, C.E.A., Irajian, G. and Heidarlo, M.N. (2016) Antimicrobial resistance of Listeria monocytogenes isolated from seafood and humans in Iran. Microb. Pathog., 
100: 70-74.

29. Sanlıbaba, P., Tezel, B.U. and Çakmak, G.A. (2018) Prevalence and antibiotic resistance of Listeria monocytogenes isolated from ready-to-eat foods in Turkey. J. Food Qual., 1: 1-9.

30. Noll, M., Kleta, S. and Dahouk, S. (2018) Antibiotic susceptibility of 259 Listeria monocytogenes strains isolated from food, food-processing plants and human samples in Germany. J. Infect. Public Health. 11(4): 572-577.

31. Hakenbeck, R. and Hof, H. (1991) Relatedness of penicillin-binding proteins from various Listeria species. FEMS Microbiol. Lett., 84(2): 191-196.

32. Ryser, E.T. and Marth, E.H. (2007) Listeria, Listeriosis, and Food Safety. 3rd ed. CRC Press, US. p896.

$* * * * * * * *$ 